\title{
El proceso de normativización de la lengua gallega
}

\author{
Manuel GonZÁlez GonZÁlez
}

UNIVERSIDAD DE SANTIAGO

Al hablar de normativización és necesario tener presente que estamos hablando de tres lenguas, el catalán el eusquera y el gallego, cada una de ellas con problemas específicos, pero unidas por el hecho de que en un período histórico no demasiado lejano estuvieron desposeídas de las prerrogativas y del apoyo que a cualquier lengua le confiere el respaldo de un estado. Después de vivir épocas de normalidad en sus respectivos territorios, estas lenguas se han convertido en lenguas minorizadas, es decir, en lenguas que se han visto privadas de alguno de los derechos o de las funciones habitualmente reconocidos a las lenguas normalizadas.

Digo esto porque del tema de la normativización - y estoy utilizando este término en un sentido equivalente al de «corpus planing», se puede hablar de cualquier lengua del mundo (inglés, francés, italiano, etc.), pero creo que los problemas que habría que abordar en el caso de las lenguas normalizadas y en el de las leguas minorizadas no serían exactamente los mismos o, en todo caso, no tendrían el mismo tratamiento.

En el caso del gallego el trabajo de normativización debe, a mi juicio, abordar al menos los tres problemas siguientes:

a) La grafización o representación gráfica del sistema fonológico de la lengua;

b) La estandarización o creación de un modelo más o menos uniforme supradialectal y no marcado socialmente, que será el que se utilice fundamentalmente en las relaciones de tipo formal. La estandarización 
debe abarcar el ámbito fonético-fonológico, el morfosintáctico y el léxico;

c) La modernización, sobre todo, léxica, que dé respuesta a las necesidades expresivas y comunicativas de la vida actual.

Cuando después de unos siglos prácticamente ágrafos en gallego, se comienza de nuevo en el XVIII a utilizar nuestra lengua en la literatura, pero sobre todo a mediados del siglo XIX cuando se produce un Rexurdimento cultural y literario del gallego, los escritores no encuentran un modelo lingüístico en que basarse. Por ello no debe producirnos extrañeza que los primeros escritores del Rexurdimento utilicen fundamentalmente su variedad dialectal. Por poner un ejemplo suficientemente conocido; la lengua de Rosalía de Castro es fundamentalmente la lengua hablada en la zona sudoriental de Santiago. Ello no quiere decir que no hubiese en Rosalía una voluntad de escribir en un gallego supradialectal, pero, como todos los que escriben sin una tradición gráfica, tenía dificultades insuperables. Los escritores posteriores van superando progresivamente este carácter localista y formando una especie de coiné literaria de carácter supradialectal, aunque casi siempre conserven, como es natural, ciertos rasgos de su habla local. Esto empieza a notarse ya en $\mathrm{Cu}$ rros Enríquez y, en mayor medida, en Pondal, Leiras Pulpeiro, etc., de tal modo que cuando llegamos a los escritores de la generación Nós apenas quedan residuos localistas.

El gallego común, diría mejor el gallego literario, es pues una convención que a lo largo del siglo XIX y primeras décadas del XX se va formando espontáneamente y que, espontáneamente, se va imponiendo.

A pesar de la unidad básica en la lengua de estos escritores, sienten la necesidad de un estándar lingüístico, pero Galicia no tuvo una institución, una ciudad, un escritor o gramático que fuesen capaces de provocar la aceptación por todos del gallego que utilizaban o proponían. De ahí los lamentos de Manuel Murguía, en su Historia de Galicia (1865), cuando dice que se «necesitaría un gran poeta, al mismo tiempo que un gran conocedor de nuestra lengua, costumbres y sentimientos, para que nos diese, no sólo el modelo de nuestra poesía, sino también de nuestra lengua literaria»; o de Nicolás Taboada, en 1893: «Aquí nos hace falta un Dante para fijar nuestro idioma».

En cambio, X. M. Pintos proponía en su obra A gaita gallega (1853) que el gallego unitario saliese de la reunión en un consistorio de tres orensanos, tres compostelanos, tres pontevedreses y tres lugueses.

Saco y Arce y Curros Enríquez, entre otros, se manifestaron repetidamente por la necesidad de crear una Academia Gallega que fijase y depurase la 
lengua. Por fin, en 1906, después de varios intentos frustados, fue constituida la Real Academia Galega. Cuando Curros escribe a Murguía para que, como presidente de una comisión de representantes de Galicia, organice la Academia, le señala como objetivo prioritario el de «formar el Diccionario y la Gramática de nuestra lengua». En el discurso de inauguración descrito por Murguía se reconocía también que la Academia había sido fundada especialmente "para recoger en Galicia su verdadero léxico, dar a conocer su gramática y afirmar su existencia». Y así se crea la Real Academia Galega con una magnífica inscripción en su emblema «Colligit, expurgat, innovat». Pero los deseos de sus fundadores fueron cumplidos sólo muy parcialmente.

Como he dicho. a pesar de todos estos problemas, se llegó (al menos en la literatura) durante el siglo XIX y primer tercio del XX a la constitución de un gallego apenas marcado dialectalmente, con restauraciones muchas veces adecuadas, aunque también con una notable presencia del castellano, reflejada en la aceptación del préstamo directo o, como reacción contra él, en el hipergalleguismo y la pseudoevolución.

Esta situación continúa en general en la postguerra, sin que haya cambios acusados hasta la década comprendida entre 1960 y 1970 . En el año 1963 se produce un hecho que será decisivo en el futuro: la creación de una sección de filología en la Universidad de Santiago. De aquí proceden casi todos los que a partir de ese momento han participado en la modernización del gallego, cualquiera que sea su punto de vista. En 1970 la R.A.G. publica las Normas ortográficas e morfolóxicas do idioma galego, que canonizaban las soluciones linguísticas adoptadas en sus publicaciones por la Ed. Galaxia, creada en 1950 por un grupo de intelectuales galleguistas y federalistas, entre los que se encontraban R. Piñeiro, X. Isla Couto, F. Fernández del Riego, Marino Dónega, etc. Y ese mismo año 1970 se crea el Instituto da Lingua Galega y se dota la primera cátedra de Lingua e Literatura Galegas en la Facultad de Filología de Santiago.

Los estudios realizados durante estos años en la Universidad de Santiago sobre las hablas gallegas y la lengua literaria ofrecían por primera vez una base sólida sobre la que trabajar. Esto, unido a que se veía en el horizonte no lejano un cambio significativo en la situación institucional del gallego, animó al Instituto da Lingua Galega a la elaboración de un método de aprendizaje del gallego en tres volúmenes (Galego l, 2,3). Cuando en 1971 el ILG publica el Galego 1, las normas que se siguen son prácticamente las mismas de la R.A.G., aunque con ciertas modificaciones, sobre todo en la selección de variantes morfológicas y léxicas, así como en la acomodación de cultismos, aspectos que en las normas de la R.A.G. aparecían superficialmente tratados o no se planteaban. Estas diferencias de matiz, realmente insignificantes (porque ambas normativas partían del mismo principio: la elaboración de un es- 
tándar a partir de la realidad del gallego vivo y de la tradición literaria del gallego moderno, debidamente depurados de elementos espúreos innecesarios), provocaron no obstante que en la sociedad gallega se contrapusieran ambas normativas.

Es necesario superar este problema, porque todos éramos conscientes del cambio de status que se estaba produciendo en el gallego, que comenzaba a ser materia de enseñanza fuera de la universidad (primero en cursos libres, organizados por instituciones no oficiales, después como material experimental en la enseñanza primaria y finalmente como materia obligatoria en la enseñanza primaria y media), y era previsible que muy pronto se le abrirían las posibilidades de ser lengua de la administración. Para la normalización de nuestra lengua la multiplicidad de normas era un obstáculo notable. Con la intención de superar este problema, el I.L.G. hizo una convocatoria abierta dirigida a los lingüistas, escritores e intelectuales que, desde posturas diferentes, estaban interesados por el problema de nuestra lengua, para participar en unos seminarios filológicos semanales, que tuvieron lugar entre diciembre de 1976 y junio de 1977 en Santiago. El resultado de estas reuniones fue la publicación de las Bases prá unificación das normas lingüísticas do galego, con el compromiso de que estos acuerdos serían respetados por todos los participantes. Pero lo cierto es que tal compromiso nunca fue cumplido por algunos, y pronto dejó de serlo por otros.

La situación era realmente delicada y era necesario superarla. El paso definitivo en la normativización del gallego se daría con el acuerdo de la Real Academia Galega y del Instituto da Lingua Galega en materia de unificación ortográfica y morfológica, aprobado en una sesión conjunta de ambas instituciones el día 3 de julio de 1982. Las Normas ortográficas e morfológicas do idioma galego, salidas de tal acuerdo fueron declaradas oficiales por la Xunta de Galicia en 1983, y, casi al mismo tiempo, el Parlamento de Galicia aprueba por unanimidad la Lei de Normalización Lingüística, en la que se recoge que la R.A.G. es el organismo competente en las cuestiones de corrección lingüística del gallego.

Estas normas consiguieron un alto grado de aceptación en la sociedad, pero no voy a ocultar que también existen algunos sectores que las combaten, y por razones distintas:

1. Hay un sector muy minoritario, y sin prácticamente ninguna incidencia social, que se opone a las normas oficiales por razones de ideología lingüística. Podemos decir que hay dos filosofías de base con respecto al gallego: los partidarios del gallego identificado y los partidarios del gallego satelizado. 
Los partidarios del gallego identificado basan sus argumentos de independencia en que existen divergencias lingüísticas tan notables entre el gallego y el portugués que reducir el gallego a variante del portugués sólo se podría hacer a costa de una desnaturalización muy alta. Pero se basan, además, en la conciencia de la inmensa mayoría de los gallegos de que hablan un idioma diferente. La normativa que defiende un gallego identificado viene siendo la cristalización de lo que era el código del gallego escrito desde el Rexurdimiento hasta la actualidad. Podemos decir que casi todo cuanto fue impreso en gallego moderno partió básicamente de un gallego independiente. Actualmente la normativa identificada es la oficial de la Comunidad gallega y en consecuencia se aplica en la enseñanza y en la administración, así como en los medios de comunicación. La utilizan también de modo exclusivo las editoriales que tienen mayor producción de libro gallego (Galaxia, Edicións Xerais e Ir Indo) y en buena parte también las demás.

La otra postura, la del gallego "satelizado», defiende que el gallego es una variante del portugués y por lo tanto debe producirse una reintegración del gallego en el portugués, aunque no hay acuerdo en cómo debe formularse esto lingüísticamente. Existen fundamentalmente dos posturas: a) Una, defendida por el sector clásico de la AGAL, que propone una normativa muy distanciada del gallego actual, pero también muy distante del portugués: se trata en realidad de un conglomerado de soluciones del gallego, del portugués, de la lengua medieval y otros condimentos mezclados en distintas proporciones. b) La otra, defendida por un grupo salido de la AGAL, integrado en una «Comissao para a integraçao da lingua da Galiza no Acordo da Ortografia simplificada» es defensora de adoptar para el gallego el Acuerdo de Río de Janeiro. Los defensores del gallego satelizado tienen una cierta presencia en sectores muy minoritarios de la Enseñanza media y hay algún caso esporádico en la docencia universitaria.

2. Pero también dentro de los partidarios del gallego identificado existen ciertas disensiones. Existe una variante de las normas oficiales, con cierta vigencia en algunos círculos, formulada en las Orientacións para a escrita do noso idioma de la Asociación Socio-Pedagóxica Galega. Estas normas son reductibles a las normas oficiales, de las que se diferencian fundamentalmente en dos puntos: el uso del guión con los pronombres enclíticos y la acentuación. Sólo ciertos recelos extralingüísticos impiden a sus promulgadores y usuarios renunciar a estos pequeños detalles que las diferencian.

3. Existen todavía algunos partidarios de una libertad absoluta en esta cuestión y de que cada uno hable y escriba como quiera, negando la necesidad (o la posibilidad) de toda intervención normativa. Esta postura es defendida por algún escritor que considera que cualquier tipo de normativa es una limitación para su capacidad creadora. Los que así piensan no distinguen entre 
los posibles recursos estilísticos del creador, y la función social del idioma. Desde mi punto de vista, esto sería un gravísimo paso atrás y colocaría a los alumnos y aprendices del gallego ante una situación desquiciante. Es difícil imaginar la viabilidad futura del gallego sin un modelo estándar más o menos fijo que se pueda aprender en la escuela o por otros medios y al que también se pueda acceder a través de los medios de comunicación. La profusión de normativas es una lacra, y creo que una irresponsabilidad, en el proceso de normalización de una lengua que está en una posición tan vulnerable como el gallego. Creo que se trata de una dificultad real para la socialización de la lengua: la normativa lingüística no puede perder el contacto con la lengua viva. Esto, aunque de un modo intuitivo, lo veía con claridad Rafael Dieste cuando decía: «A lingua vulgar, por si soia, non é paradigma; é viveiro de formas; hai que escolmar e poñer orde; $e$ sen apouvigar ('violentar') a fala viva, amostrarlle un espello en que se vexa a si mesma, e así, se compoña».

Pero no quisiera, después de dibujar este panorama, dejar en el aire la idea de que en Galicia la situación es caótica. No es así. La Normativa oficial es la única que goza de un amplio apoyo social, y progresivamente se están incorporando a ella muchos defensores de otras vías ortográficas.

Yo creo que en este momento el problema de la grafización, a pesar de ciertas disidencias, está en camino de resolverse.

En el ámbito de la estandarización, considero que en el campo morfosintáctico apenas existen ya problemas de normativización, y se encuentra en estado notablemente avanzado el problema de la estandarización del léxico común: la selección de variantes, la eliminación de castellanismos y voces espúreas innecesarias, la depuración de inventos etc. Pero no pasa lo mismo con la estandarización de la ortofonía, entendiendo esta en el sentido más amplio: ¿Qué hacer con un fenómeno como el de la gheada, que abarca aproximadamente el $80 \%$ del territorio gallego? ¿Cómo debe pronunciarse [dènte] o [dénte], [sògro] o [sogro]? ¿Cuales son los esquemas entonativos del gallego? Estos temas que pudieran parecer baladíes, no lo son en realidad, sobre todo si se tiene en cuenta la importancia de los medios de comunicación oral, como la radio y la televisión, que están ejerciendo una influencia enorme sobre la lengua de toda la población. Y, a veces, escuchando alguna emisión televisiva, a pesar de que se esté utilizando una morfosintaxis gallega, un léxico gallego, yo tengo dudas de que aquello que oigo sea realmente gallego; o, cuando menos, resulta un gallego extraño; y es precisamente por una orfonía incorrecta.

Por último, en el problema de la modernización del léxico se están haciendo cosas. La lexicografía gallega actual tiene ante si el desafío urgente de dotar a nuestra lengua de la capacidad para expresar con voz propia (e insisto, 
en lo de voz propia) todos los nuevos conceptos y objetos con los que nos está bañando el mundo actual. En los últimos años proliferan léxicos gallegos especializados (de la electricidad y la electrónica, de matemáticas, física y química, de ciencias naturales, de geografía, etc.), pero las soluciones que en ellos se proponen en muchos casos creo que no están suficientemente estudiadas y maduradas.

Para la actualización del léxico hay que valerse de las técnicas y los recursos que nos ofrece la llamada neología consciente. Las posibilidades son muchas, y no es ahora el momento de ahondar en este tema, pero hay que dilucidar cuándo es conveniente acudir al préstamo externo o xenismo, cuándo es más funcional el calco o traducción del préstamo, cuándo se debe echar mano del cultismo latino o griego, cuándo es preferible la revitalización de un arcaísmo, o cuándo es necesaria la creación autóctona para asegurar la identidad de la lengua ( $\mathrm{y}$, en este caso, cuándo es aconsejable la derivación, la composición, la sinapsia, la ampliación o cambio de sentido de una palabra, etc., etc.).

Como puede verse, son muchas todavía las tareas pendientes en el proceso global de normativización de nuestra lengua, que supera ampliamente las discusiones ortográficas, aunque estas sean las que trascienden más fácilmente a la opinión pública.

El camino de la normalización del gallego es difícil y espinoso, pero puedo asegurarles que lo recorreremos, porque la ilusión, a pesar de las discrepancias, es mayor que las dificultades, y los gallegos tenemos claro que si aún somos gallegos es fundamentalmente por obra y gracia de nuestra lengua. 